\title{
Diethylnitrosamine-induced hepatic neoplasms in the fish Rivulus ocellatus marmoratus
}

\author{
John M. Grizzle*, Arunthavarani Thiyagarajah** \\ Department of Fisheries and Allied Aquacultures, Alabama Agricultural Experiment Station, Auburn University, Auburn, \\ Alabama 36849, USA
}

\begin{abstract}
Hepatic lesions caused by a single or continuous exposure to diethylnitrosamine (DEN) are described in rivulus Rivulus ocellatus marmoratus, a self-fertilizing hermaphroditic fish. Hepatocellular and biliary tumors, hemangiomas, hemangiopericytomas, and metastatic thyroid celis occurred in livers of rivulus first exposed when $1 \mathrm{~d}$ old (larvae) or $30 \mathrm{~d}$ old (juveniles). Basophilic, eosinophilic, and 3 types of vacuolated-cell foci were observed before neoplasms developed. Spongiosis hepatis also occurred in livers of DEN-exposed fish. Rivulus first exposed as larvae had significantly higher incidences of cholangiocarcinomas and hemangiomas than fish first exposed as juveniles. Hepatocellular carcinomas cholangiocarcinomas, and hemangiomas were significantly more common in rivulus exposed continuously.
\end{abstract}

\section{INTRODUCTION}

Rivulus ocellatus marmoratus (common name, rivulus) develop hepatic and pancreatic neoplasms after exposure to diethylnitrosamine (DEN) (Koenig \& Chasar 1984, Park \& Kim 1984, Thiyagarajah \& Grizzle 1985,1986 a). Rivulus was formerly known by the junior synonym Rivulus marmoratus (Seegers 1984). Exposure times to DEN in previous experiments with rivulus varied from 2 h (Park \& Kim 1984) to 8 mo (Thiyagarajah \& Grizzle 1986a), and fish age at the beginning of exposure ranged from $1 \mathrm{~d}$ (Thiyagarajah \& Grizzle 1986a) to 7 mo (Thiyagarajah \& Grizzle 1985). These earlier studies indicated that the fish age at initial exposure and length of exposure affect the types and incidence of tumors. For example, pancreatic adenocarcinomas were reported only after continuous exposure for several weeks, with exposures beginning soon after hatching (Thiyagarajah \& Grizzle 1986a). However, the effects of exposure length and age at initial exposure have not been adequately investigated. Reasons for using rivulus, a hermaphroditic cyprinodontiform fish, in carcinogenesis studies were

- Addressee for reprint requests

- Present address: College of Veterinary Medicine, PO Drawer V, Mississippi State University, Mississippi State, Mississippi 39762, USA reviewed previously (Koenig \& Chasar 1984, Park \& Kim 1984, Thiyagarajah \& Grizzle 1985).

This study compares the DEN-induced hepatic neoplasms of rivulus first exposed when 1 or $30 \mathrm{~d}$ old and then exposed for $1 \mathrm{wk}$ or continuously until necropsied. These exposure protocols are different to those used in previous reports of hepatic neoplasms in DEN-exposed rivulus. New observations on hepatic lesions observed before the development of neoplasms are also described. Pancreatic neoplasms in the fish exposed in this experiment were previously reported (Thiyagarajah \& Grizzle 1986a).

\section{MATERIALS AND METHODS}

Rivulus were reared in our laboratory under cultural conditions described by Koenig \& Chasar (1984). Each fish was kept in $100 \mathrm{ml}$ of synthetic seawater prepared by dissolving $14 \mathrm{~g}$ 'Marine Mix' (Hawaiian Marine Mix Inc., Houston, Texas, USA) in 11 of distilled water. The $\mathrm{pH}$ of the water was 7.8 and the temperature ranged between 22 and $29^{\circ} \mathrm{C}$. Adults were fed frozen Artemia (San Francisco Bay Brand, California) and juveniles were fed newly hatched nauplii of Artemia thrice weekly

Single exposure. Forty juveniles (1-mo-old) or larvae (1-d-old) per concentration were exposed to initial con- 
centrations of 810 ( $7 \mathrm{~d} \mathrm{LC}_{10}$ for juvenile rivulus), 270 , 130, or $0 \mathrm{mg} 1^{-1}$ DEN via water for $1 \mathrm{wk}$ and then transferred to uncontaminated water. DEN concentrations were quantified with a gas chromatograph and flame ionization detector (Lunn et al. 1983). During a 1 wk exposure, concentrations decreased by ca $35 \%$ in these concentrations. Fish were kept individually in $11.4 \mathrm{~cm}$ diameter, stackable, glass culture dishes containing $100 \mathrm{ml}$ of synthetic seawater. At the beginning of the experiment, 5 fish per concentration were designated for each monthly sample. The abdominal cavity of survivors was opened and the viscera were examined in situ using a dissecting microscope. The fish were then fixed whole in Bouin's or Carnoy's fixative or $10 \%$ buffered formalin. Selected pieces of liver lesions were fixed in $3 \%$ glutaraldehyde for electron microscopy.

Continuous exposure. Forty juveniles or larvae per concentration (5 in 1 dish) were exposed continuously, for up to $8 \mathrm{mo}$, to initial concentrations of 50 (6 wk LC 10 for juvenile rivulus), 17,9 , or $0 \mathrm{mg} \mathrm{I} \mathrm{I}^{-1}$ DEN. DEN solutions were changed weekly, and the concentrations were quantified as in the single-exposure experiment. During a $1 \mathrm{wk}$ exposure, DEN concentrations decreased by ca $10 \%$ in these concentrations. The sampling schedule, sample sizes, and protocol for examination of fish were the same as in the singleexposure experiment.

Light microscopy. Whole fish were decalcified in a formic acid-sodium citrate mixture and embedded in paraffin. Serial sections were cut at $5 \mu \mathrm{m}$ and stained with hematoxylin and eosin ( $\mathrm{H} \& \mathrm{E}$ ). Selected sections were stained with periodic acid Schiff's (PAS) reagents, Masson's or Mallory's trichrome, picro-ponceau stain for elastic fiber, and Gomori's reticulin stain (Humason 1979). The Prussian blue technique was used to demonstrate stainable iron (Humason 1979). Selected pieces of liver were cryosectioned and stained with oil red $O$ for lipid and PAS for glycogen. The gold chloride reaction and fluorescence microscopic analysis (Wake 1971) was used to determine the chemical characteristics of perisinusoidal stellate cells. Thick sections $(2 \mu \mathrm{m})$ of epoxy-embedded tissues for light microscopy were stained with toluidine blue.

Electron microscopy. Glutaraldehyde-fixed tissues were post-fixed in $1 \%$ osmium tetroxide and washed in phosphate buffer, dehydrated in a graded series of ethanol, and embedded in epoxy. Sections were cut at $60 \mathrm{~nm}$ and contrasted with uranyl acetate and lead citrate.

Statistical analysis. Fisher's exact probability test was used to compare frequencies of lesions in fish from various treatment groups and to compare frequencies of various types of lesions. Differences were considered significant when $p<0.05$.

\section{RESULTS}

All larvae exposed to $810 \mathrm{mg} \mathrm{l}^{-1}$ DEN for $1 \mathrm{wk}$ died by Day 18 post-exposure and were not examined histologically. For other concentrations, cumulative mortalities of larvae during the first $20 \mathrm{wk}$ of the experiment were 20 to $50 \%$. For the same time period, juveniles exposed to DEN had 25 to $30 \%$ mortality except for 60 to $65 \%$ mortality of juveniles continuously exposed to 9 or $17 \mathrm{mg} \mathrm{l}^{-1}$. Mortalities of control juveniles and larvae were 10 and $20 \%$, respectively. Accurate comparisons of mortality in different treatments after $20 \mathrm{wk}$ were not possible because of the small remaining sample sizes.

Lesion incidence was not proportional to exposure concentration, except as noted below. Data are summarized with results of the various concentrations combined (Tables 1 and 2)

Table 1. Rivulus ocellatus marmoratus. Incidence of preneoplastic lesions in rivulus after a single exposure or continuous exposure to DEN. Incidence presented as number of fish with lesion/number of fish exposed. Fish were first exposed while larvae (L) or juveniles $(\mathrm{J})$. Thes: lesions were not observed in control fish

\begin{tabular}{|c|c|c|c|c|c|c|}
\hline \multirow{2}{*}{$\begin{array}{l}\text { Lesions and } \\
\text { treatment }\end{array}$} & \multicolumn{2}{|c|}{$4-12 w k$} & \multicolumn{2}{|c|}{$16-24 w k$} & \multicolumn{2}{|c|}{$28-32 w k$} \\
\hline & $\mathrm{L}$ & $\mathrm{J}$ & I. & $\mathrm{J}$ & $\mathrm{L}$ & $\mathrm{J}$ \\
\hline \multicolumn{7}{|l|}{ Basophilic foci } \\
\hline 1 wk exposure & $2 / 12$ & $2 / 28$ & $0 / 14$ & $4 / 36$ & $2 / 12$ & $1 / 20$ \\
\hline Continuous exposure & $3 / 26$ & $2 / 32$ & $1 / 32$ & $3 / 23$ & $0 / 14$ & $0 / 10$ \\
\hline \multicolumn{7}{|l|}{ Eosinophilic foci } \\
\hline 1 wk exposure & $1 / 12$ & $0 / 28$ & $0 / 14$ & $0 / 36$ & $0 / 12$ & $0 / 20$ \\
\hline Continuous exposure & $1 / 26$ & $1 / 32$ & $0 / 32$ & $0 / 23$ & $0 / 14$ & $0 / 10$ \\
\hline \multicolumn{7}{|l|}{ Vacuolated-cell foci } \\
\hline 1 wk exposure & $2 / 12$ & $2 / 28$ & $5 / 14$ & $12 / 36$ & $2 / 12$ & $7 / 20$ \\
\hline Continuous exposure & $2 / 26$ & $7 / 32$ & $9 / 32$ & $5 / 23$ & $7 / 14$ & $5 / 10$ \\
\hline
\end{tabular}


Table 2. Rivulus ocellatus marmoratus. Incidence of hepatic neoplasms in rivulus after a single exposure or continuous exposure to DEN. Incidence presented as number of fish with lesion/number of fish exposed. Fish were first exposed while larvae (L) or juveniles (J). Neoplasms were not observed in control fish

\begin{tabular}{|c|c|c|c|c|c|c|}
\hline \multirow{2}{*}{$\begin{array}{l}\text { Lesions and } \\
\text { treatment }\end{array}$} & \multicolumn{2}{|c|}{$4-12 w k$} & \multicolumn{2}{|c|}{$16-24 \mathrm{wk}$} & \multicolumn{2}{|c|}{$28-32 w k$} \\
\hline & L & J & $\mathrm{L}$ & $\mathrm{J}$ & L & $J$ \\
\hline \multicolumn{7}{|l|}{ Hepatic adenoma: } \\
\hline 1 wk exposure & $0 / 12$ & $0 / 28$ & $6 / 14$ & $8 / 36$ & $1 / 12$ & $7 / 20$ \\
\hline Continuous exposure & $2 / 26$ & $0 / 32$ & $8 / 32$ & $4 / 23$ & $3 / 14$ & $0 / 10$ \\
\hline \multicolumn{7}{|l|}{ Hepatocellular carcinoma: } \\
\hline $1 \mathrm{wk}$ exposure & $0 / 12$ & $0 / 28$ & $0 / 14$ & $1 / 36$ & $0 / 12$ & $0 / 20$ \\
\hline Continuous exposure & $1 / 26$ & $0 / 32$ & $8 / 32$ & $2 / 23$ & $7 / 14$ & $9 / 10$ \\
\hline \multicolumn{7}{|l|}{ Cholangioma: } \\
\hline 1 wk exposure & $1 / 12$ & $1 / 28$ & $4 / 14$ & $16 / 36$ & $6 / 12$ & $9 / 20$ \\
\hline Continuous exposure & $8 / 26$ & $5 / 32$ & $19 / 32$ & $20 / 23$ & $9 / 14$ & $7 / 10$ \\
\hline \multicolumn{7}{|l|}{ Cholangiocarcinoma: } \\
\hline 1 wk exposure & $0 / 12$ & $0 / 28$ & $0 / 14$ & $1 / 36$ & $0 / 12$ & $0 / 20$ \\
\hline Continuous exposure & $0 / 26$ & $0 / 32$ & $3 / 32$ & $0 / 23$ & $4 / 14$ & $0 / 10$ \\
\hline \multicolumn{7}{|l|}{ Hemangioma: } \\
\hline 1 wk exposure & $0 / 12$ & $0 / 28$ & $0 / 14$ & $0 / 36$ & $0 / 12$ & $0 / 20$ \\
\hline Continuous exposure & $0 / 26$ & $0 / 32$ & $2 / 32$ & $0 / 23$ & $2 / 14$ & $0 / 10$ \\
\hline \multicolumn{7}{|l|}{ Hemangiopericytoma: } \\
\hline 1 wk exposure & $0 / 12$ & $0 / 28$ & $0 / 14$ & $3 / 36$ & $0 / 12$ & $3 / 20$ \\
\hline Continuous exposure & $1 / 26$ & $0 / 32$ & $6 / 32$ & $0 / 23$ & $2 / 14$ & $1 / 10$ \\
\hline
\end{tabular}

\section{Gross lesions}

Larvae and juveniles exposed to a single dose of DEN and examined after 1 to 4 mo had pale or greyishwhite, soft livers. Occasionally, black or brown spots of various sizes occurred on the parietal and visceral surfaces of the liver. Several juveniles and larvae examined 5 to 8 mo after a single dose on DEN had greyish-white livers with irregular surfaces, white nodules, or cysts which always contained clear fluid and occasionally contained white, solid material. Neoplasms could not be reliably identified grossly.

Many of the fish continuously exposed to DEN were emaciated and/or had livers with greyish-white, multiple nodules or multilocular, fluid-filled cysts. Some livers had surfaces with diffuse black or brown pigments.

\section{Cytotoxic lesions}

Two types of morphologically distinct, intracytoplasmic hyaline masses were observed in hepatocytes of DEN-exposed fish. They were reticular hyaline (PASnegative acellular masses with irregular outline) and globular hyaline (PAS-positive). Cytoplasmic globular hyaline was represented by spherical or oval eosi- nophilic bodies surrounded by a clear halo. These globules usually occurred singly within the cell but occasionally were present in clusters. Both reticular hyaline and globular hyaline were present in the same liver.

\section{Preneoplastic lesions}

Vacuolated-cell (Fig. 1), eosinophilic (Fig. 2a) and basophilic (Fig. 2b) foci occurred in DEN-exposed larvae and juveniles but were not observed in control fish (Table 1).

Three types of foci consisting of cells with vacuolated cytoplasm occurred in rivulus exposed to DEN. All of these foci had morphologically altered cells containing vacuolated cytoplasm in paraffin sections, but they varied in cellular and nuclear shape, cytoplasmic content, and nuclear location. One type of focus contained swollen, spherical hepatocytes with eccentric nuclei (Fig. 1a). Examination of semi-thin epoxy sections of these foci with light microscopy indicated that the cytoplasm contained lipid, stained black by osmium, in addition to accumulations of non-osmophilic material presumed to be glycogen. A second type of focus that resembled clear-cell foci of rodents contained either normal-sized or slightly enlarged polygonal hepato- 

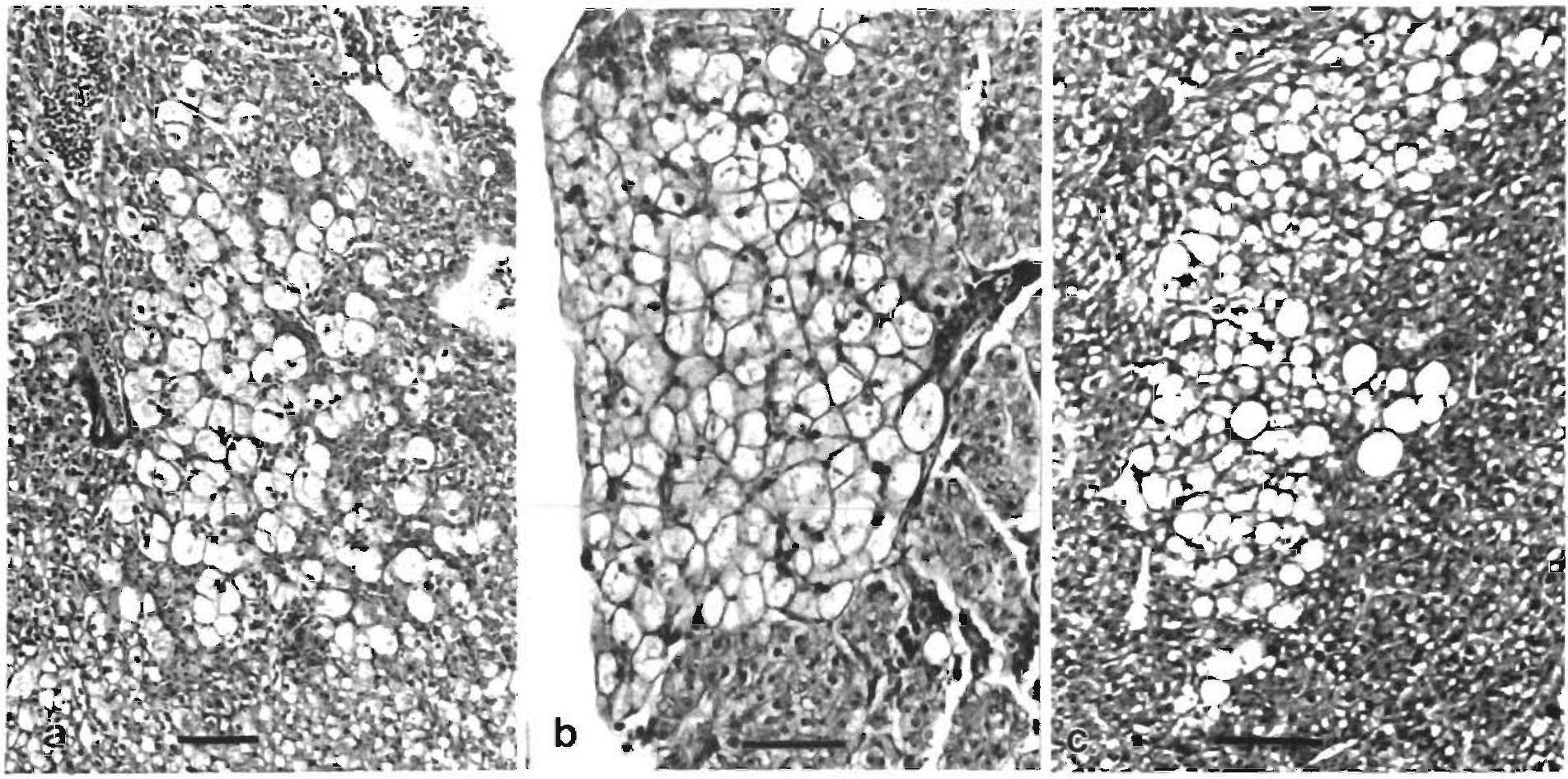

Fig. 1 Rivulus ocellatus marmoratus. Th.ree types of vacuolated-cell foci in paraffin sections of livers from DEN-exposed rivulus. $H \& E_{\text {; }}$ scale bars $=50 \mu \mathrm{m}$. (a) Focus of spherical hepatocytes with eccentric, spherical nuclei. Lipid and glycogen accumulations caused the vacuolated appearance. (b) Focus of polygonal hepatocytes with glycogen-rich cytoplasm. (c) Focus of lipid-containing cells with compressed nuclei. These cells had characteristics of perisinusoidal stellate cells

cytes containing centrally located or eccentric nuclei (Fig. 1b). Histochemical examinations revealed accumulation of glycogen and little or no lipid in the cytoplasm. The earliest these 2 types of foci were observed was $4 \mathrm{wk}$ after exposure of larvae to a single dose of $270 \mathrm{mg} \mathrm{l}^{-1}$.

A third type of vacuolated-cell focus was composed of cells containing large, spherical vacuoles; cytoplasmic lipid droplets were observed in epoxy sections. These cells were arranged around sinusoids and had peripherally located, compressed, hyperchromatic nuclei (Fig. 1c). Cells composing these foci fluoresced when exposed to ultraviolet light and stained positively with the gold chloride reaction, suggesting the presence of vitamin A. Trichrome-stained sections were positive for Type I collagen on the periphery of the foci. Silver-stained sections showed a few reticular fibers (Type III collagen). These observations indicate that these lipid-rich foci originated from perisinusoidal stellate cells (fat-storing cells or lipocytes) (Wake 1971). These foci occurred as early as $4 \mathrm{wk}$ in both juveniles and larvae exposed to a single or continuous dose of DEN irrespective of concentrations

Eosinophilic foci (Fig. 2a) consisted of pleomorphic hepatocytes containing granular, eosinophilic cytoplasm. These hepatocytes were often hypertrophied. with enlarged, hyperchromatic nuclei. Nucleoli were prominent. Eosinophilic foci were observed only between 4 and $12 \mathrm{wk}$ after the beginning of exposure (Table 1)

Basophilic foci (Fig. 2b) contained hepatocytes with basophilic cytoplasm and were usually multifocal. Basophilic foci were significantly more common than eosinophilic foci. Size of the hepatocytes in basophilic foci was normal or slightly smaller than normal. Nuclei and the trabecular pattern appeared normal. The margin of the lesion was not well defined. The earliest basophilic foci were observed in fish exposed as larvae to a single dose of $270 \mathrm{mg} \mathrm{l}^{-1}$ DEN and examined after 4 wk.

\section{Hepatocellular neoplasms}

Hepatic adenomas (Fig, 2c) occurred as a single or multiple lesion and had either a lamellar, solid or glandular form. No mitoses were observed in adenomas, and cytoplasmic properties varied from strongly basophilic to vacuolated. Compared to basophilic foci, adenomas had a better defined margin, tended to compress adjacent tissue, sometimes contained enlarged cells, and had some loss of the normal lamellar arrangement of hepatocytes. Vacuolated nuclei frequently occurred in 


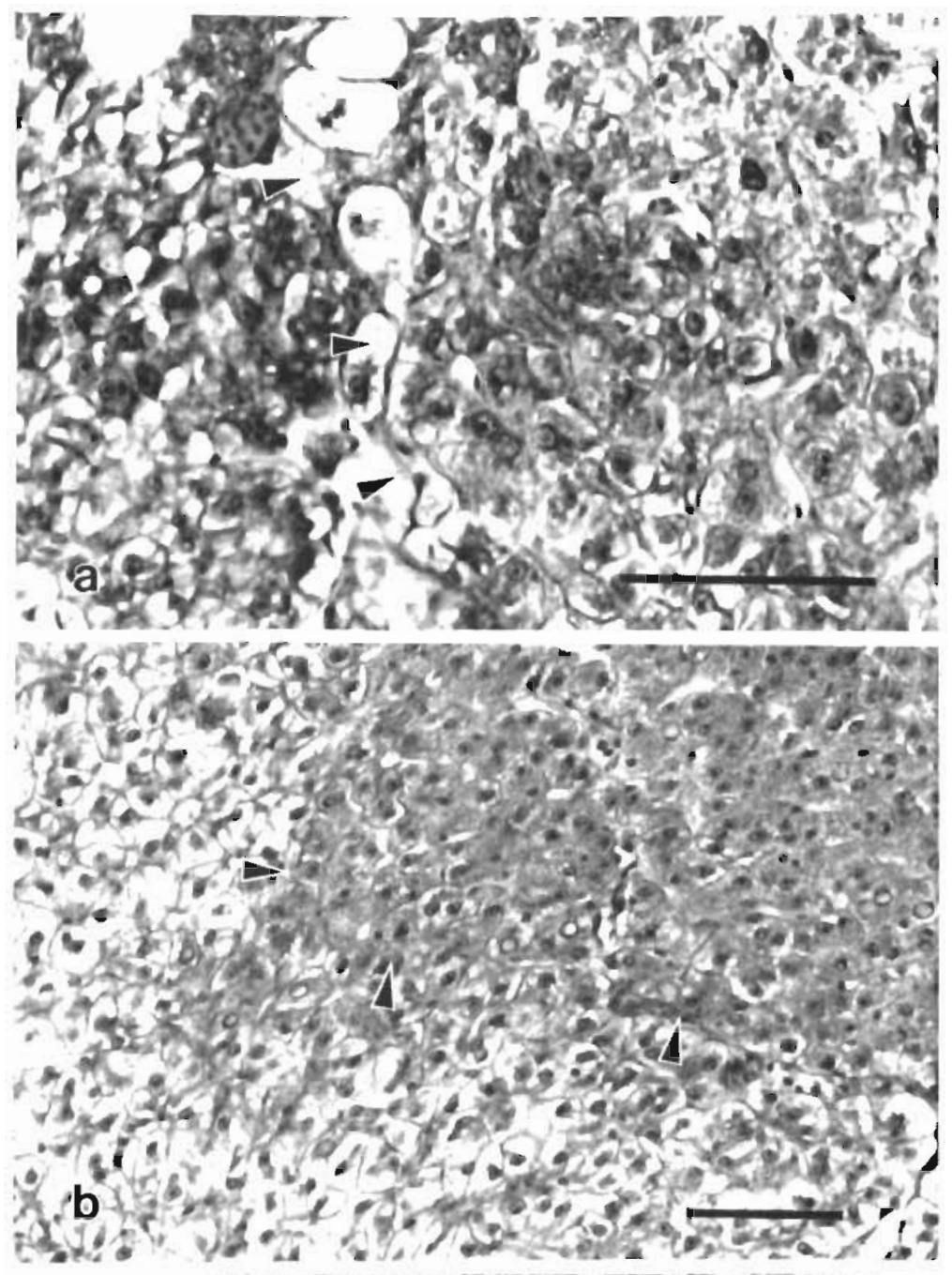

Fig. 2. Rivulus ocellatus marmoratus. Preneoplastic lesions and benign neoplasms in livers of DEN-exposed rivulus. Boundaries of lesions are indicated by arrowheads. $H \& E_{\text {; }}$ scale bars $=50$ um. (a) Eosinophilic focus of hepatocytes (b) Basophilic focus of hepatocytes. (c) Hepatocellular adenoma

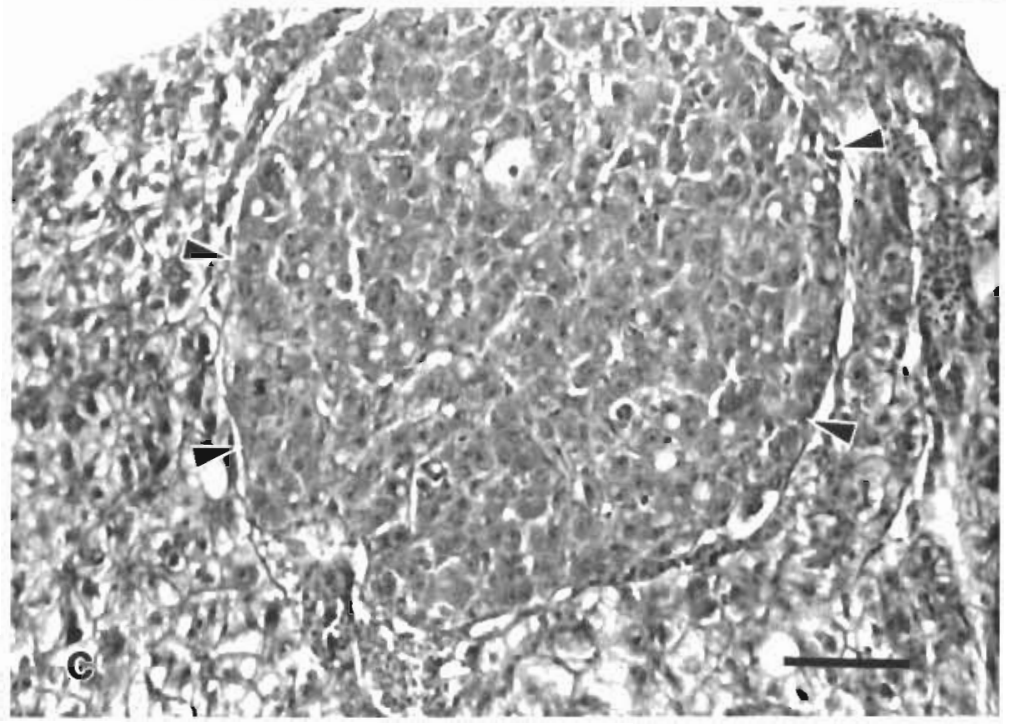


neoplastic hepatocytes. In hepatic adenomas, necrosis and fibrosis were uncommon. Hepatic adenomas were rare until after 16 wk (Table 2).

The first hepatocellular carcinoma observed was in a rivulus first exposed as a larva, exposed continuousiy to $50 \mathrm{mg} 1^{-1} \mathrm{DEN}$, and examined after $12 \mathrm{wk}$. The incidence increased in continuously exposed fish with duration of exposure (Table 2). There was a significantly higher incidence of hepatocellular carcinomas in fish (larvae or juveniles) exposed continuously than in fish exposed for $1 \mathrm{wk}$. Usually these tumors were multifocal, and either solid, glandular, or lamellar in form (Fig. 3a). Multiple nuclei were frequent, and circulating macrophages in sinusoids were common in these tumors. Features of carcinomas that distinguished them from adenomas were the lack of a definite boundary, invasion into adjacent tissue, irregular size of nuclei, and increased number of mitotic figures.

Hepatocellular carcinomas were frequently mixed with biliary tumors, resulting in mixed hepatocellularbiliary tumors. Another type of tumor consisted of spindle-shaped cells and occurred in 2 fish exposed continuously to $17 \mathrm{mg} \mathrm{l}^{-1} \mathrm{DEN}$ and examined after $32 \mathrm{wk}$ (Fig. 3b). We considered these lesions to be anaplastic hepatocellular carcinomas rather than poorly differentiated cholangiocarcinomas because there were numerous sinusoids but no apparent duct-shaped structures or basal laminae.

Ultrastructurally, well-developed hepatocellular carcinomas contained interdigitated, hepatocellular plasma membranes and enlarged intercellular spaces containing amorphous material. Compared to mitochondria in control rivulus, the mitochondria of neoplastic cells were distended and had irregularly arranged cristae. Microfilaments occupied much of the cytoplasm in some neoplastic hepatocytes (Fig. 3c). Cytoplasmic glycogen and lipid content was less than in normal hepatocytes. Bile canaliculi were dilated, had lost their microvilli, and contained amorphous, electron-lucent or granular, electron-dense material. Pericanalicular cytoplasm was thickened and contained abundant microfilaments.

Certain non-neoplastic lesions were often associated with hepatocellular tumors. Ceroid pigment in macrophage centers was common in neoplastic livers but was not found within the neoplasms nor in control livers. Inflammation, necrosis, and eosinophil infiltration occurred frequently in hepatocellular tumors but fibrosis was minimal.

\section{Spongiosis hepatis}

Spongiosis hepatis occurred in livers of DENexposed rivulus, irrespective of exposure protocol and
DEN concentrations, but was not observed in control fish. These lesions were characterized by multilocular spaces filled with pale eosinophilic granular material (Fig. 3d). The earliest spongiosis hepatis that was observed was in rivulus exposed continuously to $17 \mathrm{mg}$ $1^{-1}$ DEN and examined after $16 \mathrm{wk}$. Spongiosis hepatis was present near hepatocellular neoplasms but was also present in livers without tumors.

\section{Biliary tumors}

Unilocular or multilocular cholangiomas formed cystic or papillary structures (Table 2, Fig. 4a). The epithelium of cholangiomas was composed of a single layer of cuboidal cells with minimal to moderate amounts of eosinophilic cytoplasm and fairly uniform, round, hyperchromatic, basally located nuclei. A few mitotic figures were observed.

In addition to cholangiomas, large multilocular cystic structures composed of a single layer of flattened epithelial cells and little or no collagen occurred in some DEN-exposed rivulus livers (Fig. 4b). No mitotic figures were observed in these lesions. It was difficult to determine whether these cystic structures were simply biliary cysts or biliary cystadenomas. These lesions did not resemble adenofibrosis. Occasionally, these cystic structures were continuous with multilocular cholangiomas (Fig. 4b). Multilocular cholangiomas often contained basophilic acellular concretions, within lumina of the component cysts, that were PAS positive.

Cholangiocarcinomas (Fig. 4c) were composed of tubular structures lined by cuboidal to columnar epithelial cells containing pleomorphic nuclei and with more frequently observed mitoses than in cholangiomas. Periductal necrosis and fibrosis were common in cholangiocarcinomas. Incidence of cholangiocarcinomas was significantly higher in fish first exposed as larvae and then continuously exposed until necropsied than in other treatments (Table 2).

\section{Hemangiomas}

Cavernous hemangiomas (Fig. 5a, Table 2) were composed of large blood-filled cavities lined by a single layer of swollen endothelial cells containing hyperchromatic nuclei. Mitotic figures were rare. Peliosis (dilated sinusoids, with or without lining endothelial cells) occurred as early as $4 \mathrm{wk}$, irrespective of DEN concentration and method of administration. Although hemangiomas were uncommon during our study, the incidence was significantly higher in fish first exposed as larvae and exposed continuously than in fish exposed as juveniles or in fish exposed for $1 \mathrm{wk}$. 


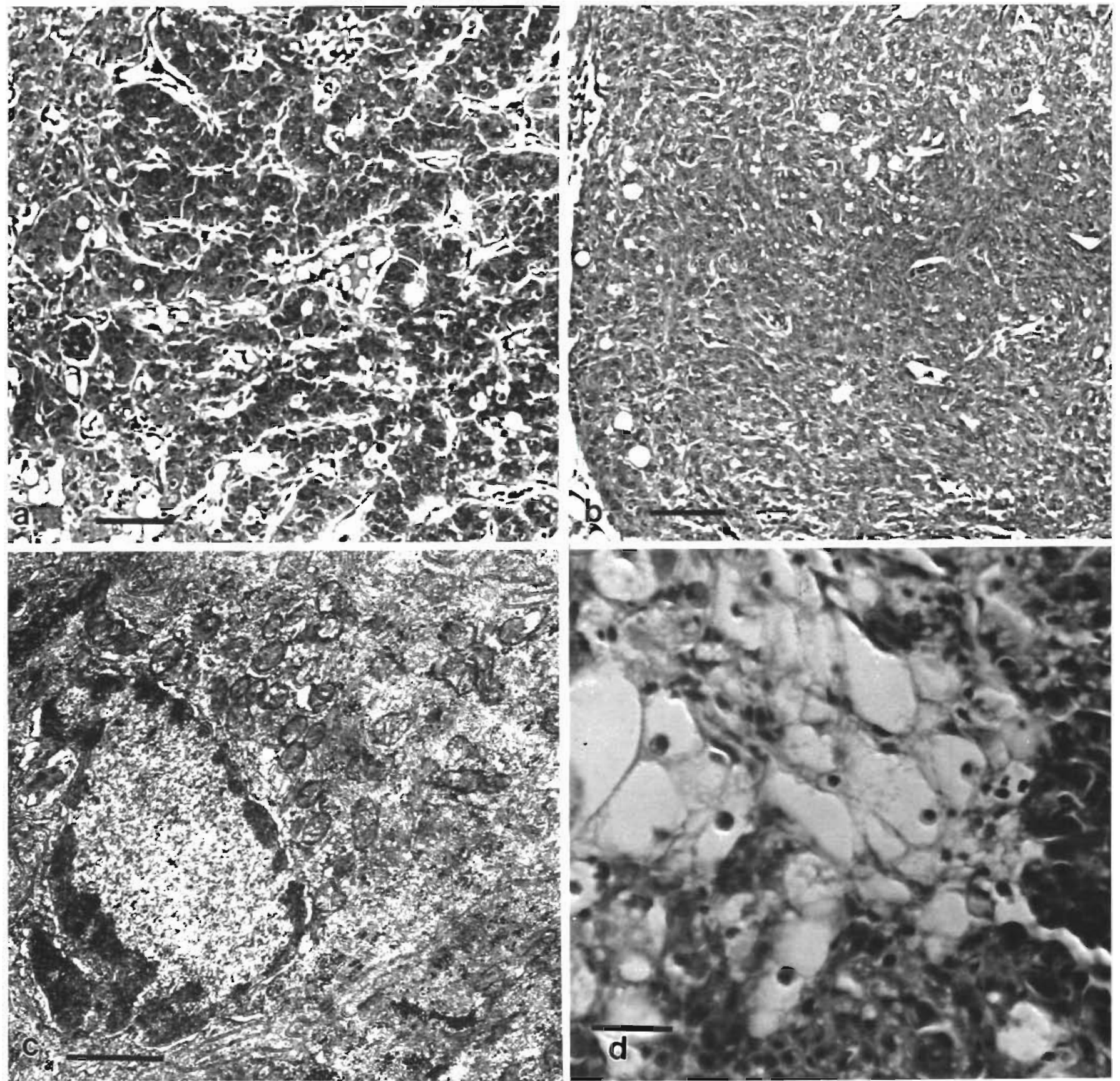

Fig. 3. Rivulus ocellatus marmoratus. Hepatic neoplasms in DEN-exposed rivulus. (a) Trabecular form of hepatocellular carcinoma. H\&E; scale bar $=50 \mu \mathrm{m}$. (b) Anaplastic carcinoma of spindle-shaped hepatocytes. H\&E; scale bar $=50 \mu \mathrm{m}$. (c) Transformed hepatocyte with abundant microfilaments in the cytoplasm. EM; scale bar $=1.0 \mu \mathrm{m}$. (d) Spongiosis hepatis lesion in DEN-exposed liver of rivulus. The cystic spaces contained eosinophilic material. $\mathrm{H} \& \mathrm{E}_{\mathrm{i}}$ scale bar $=20 \mu \mathrm{m}$

Hemangiopericytomas

Hemangiopericytomas (Fig. 5b) occurred in DENexposed larvae and juveniles (Table 2). These lesions were often observed in the tip of the posterior projection on the right side of the liver and also in areas near the anterior border of the liver
Diagnosis of these sarcomas was based on their histologic similarity to hemangiopericytomas previously described in DEN-exposed fish (Schultz \& Schultz 1985, Couch \& Courtney 1987). The predominant cell type was spindle-shaped, contained moderate amounts of eosinophilic cytoplasm, and had large nuclei with a prominent, centrally located nucleolus. Tumor cells 


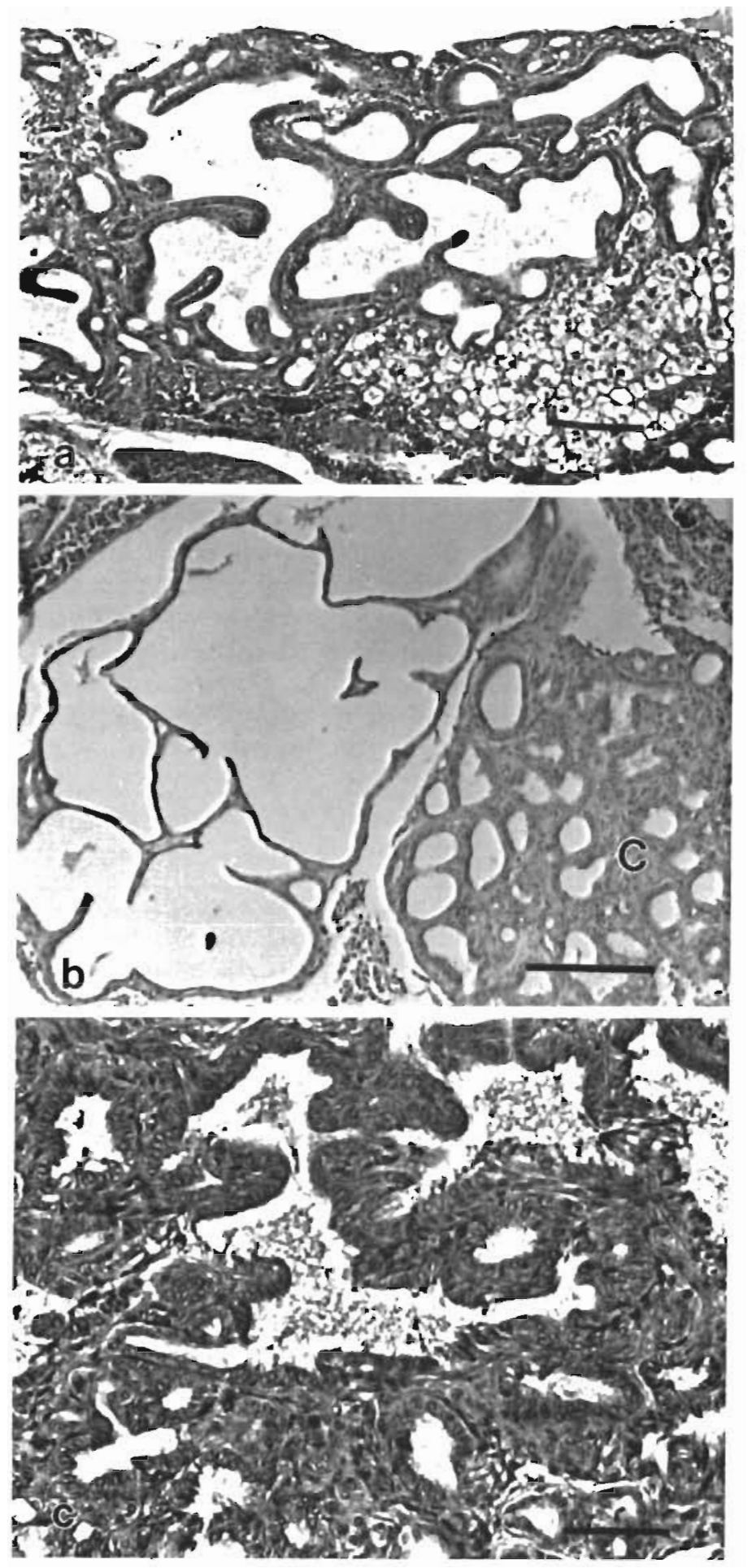

Fig. 4. Rivulus ocellatus marmoratus. Biliary tumors in DEN-exposed rivulus liver. H\&E. (a) Multilocular cystic cholangioma. Scale bar $=100 \mu \mathrm{m}$. (b) Cystic structures lined by single layer of flattened cells and cholangioma (C). Scale bar $=100 \mu \mathrm{m}$. (c) Cholangiocarcinoma. Scale bar $=50 \mu \mathrm{m}$ were often in whorls of collagen and reticulin around small blood vessels (Fig. 5b), although this arrangement was not prominent in all sections. This tumor type also had whorls formed by multiple layers of spindle-shaped cells that contained lipid-rich cytoplasm. Tumor whorls were separated by tracts of irregularly arranged fibrous tissue. Elastic fibers in increased amounts ran in random directions within the tracts of fibrous tissue. In some areas, tumor cells were densely packed with little or no intercellular space, but in other areas, intercellular material was myxoid in appearance. This type of tumor often invaded the hepatic parenchyma. 
Fig. 5. Rivulus ocellatus marmoratus. (a) Mixed hepatocellular carcinomas and cavernous hemangroma (arrowheads) in the liver of a DEN-exposed rivulus. H\& $E_{i}$ scale bar $=50 \mu \mathrm{m}$. (b) Hemangiopericytoma in DENexposed rivulus. Tumor cells were arranged in whorls around capillaries. H\&E; scale bar $\equiv 100 \mu \mathrm{m}$ (c) Metastatic thyroid in the liver of a DEN-exposed rivulus $H \& E$, scale bar $=50 \mu \mathrm{m}$
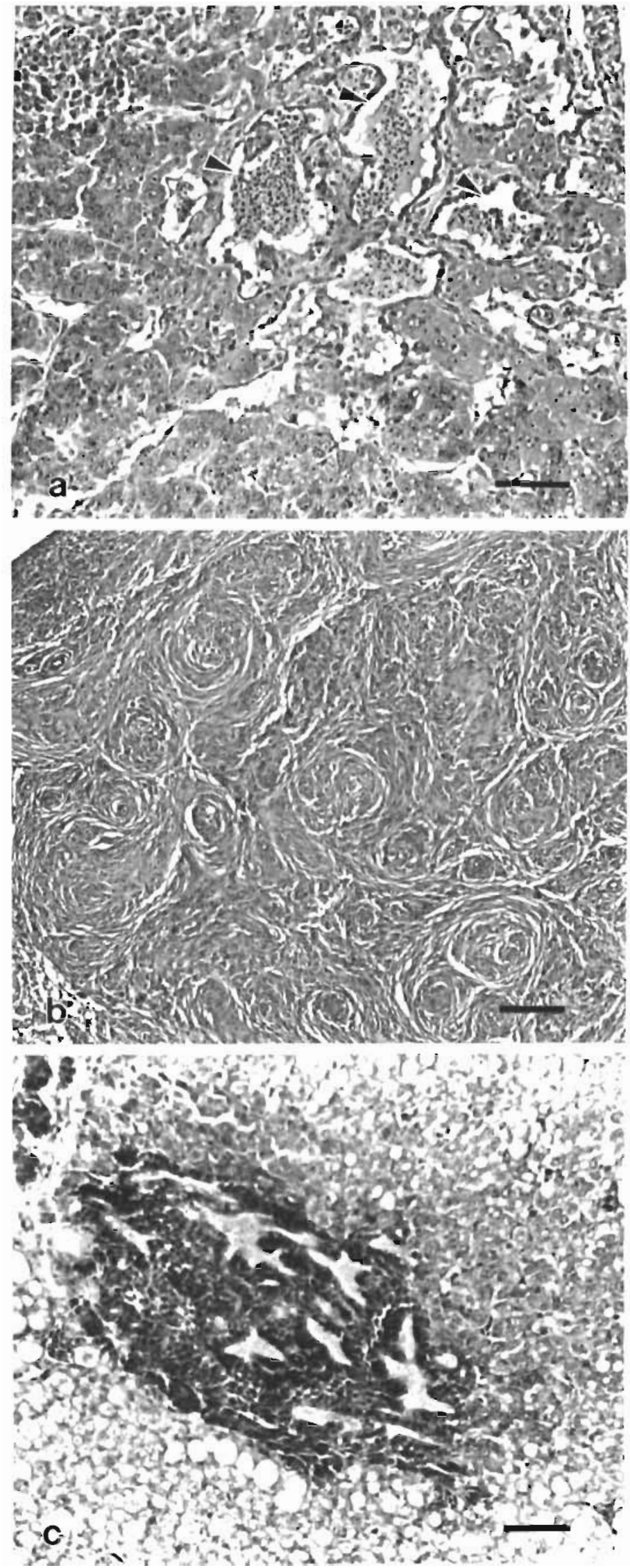


\section{Thyroid tissue in the liver}

Thyroid follicles in the liver (Fig. 5c) were obscrved only in rivulus exposed continuously to DEN. Thyroid tissue was not observed in livers of control fish nor in fish without enlarged masses of thyroid follicles in the sub-pharyngeal region. Thyroid tissue was observed in the livers of 1 juvenile rivulus and 6 rivulus first exposed when $1 \mathrm{~d}$ old. Thyroid was also observed in mesentery near the liver. In some fish, ectopic thyroid tissue was histologically similar to enlarged thyroid masses occurring ventral to the pharynx, but in other fish, ectopic thyroid was poorly differentiated and had a distorted follicular pattern (Fig. 5c).

\section{DISCUSSION}

Morphologically similar hepatocellular neoplasms develop in fish (Stanton 1965, Ishikawa et al. 1975, Egami et al. 1981, Khudoley 1984, Parland \& Baumann 1985, Couch \& Courtney 1987) including rivulus (Koenig \& Chasar 1984, Park \& Kim 1984, Thiyagarajah \& Grizzle 1985), and mammals (Argus \& Hoch-Ligeti 1961, 1963, Rapp et al. 1965, Kelly et al. 1966) exposed to DEN. Some variation has been reported in the reaction of hepatocytes to DEN but these differences are probably related to dose, duration and schedule of administration, age of experimental animals at onset of exposure, and length of time between exposure and necropsy. A possible difference between the responses of fish and mammals is less frequent metastasis of piscine hepatocellular tumors (Sinnhuber et al. 1977). although metastasis has been reported (Ashley \& Halver 1963, 1968, Hendricks et al. 1984), usually in older fish. Implanted metastases of hepatobiliary or vascular tumors were not found during the present study.

Three types of vacuolated-cell foci were described in this study. Each of these types was distinct both histochemically and in routinely stained paraffin sections. One type of focus, characterized by glycogenic overload without excess cytoplasmic lipid, was morphologically similar to clear-cell foci suspected of being preneoplastic lesions in rodents (Bannasch et al. 1980, Stewart et al. 1980). However, clear-cell foci do not appear to be associated with neoplastic development in rainbow trout (Hendricks et al. 1984). Another type of focus in rivulus also involved glycogenic overload of hepatocytes, but these cells had cytoplasmic lipid accumulation causing a displacement of the nucleus to the cell periphery. Both of these types of foci involved glycogen accumulation in hepatocytes and apparently differed only in the amount of excess cytoplasmic lipid.
Nuclear deposits of glycogen and lipid, which are common in hepatocytes of unexposed rivulus (Thiyagarajah \& Grizzle 1986h), occurred in an occasional hepatocyte within these foci. The third type of vacuolated-cell focus in rivulus resulted from excessive lipid accumulation in perisinusoidal stellate cells. In some cases, the large size of the lipid-filled cells resulted in a resemblance to lipoma. Hendricks et al. (1984) described vacuolated-cell foci in livers of rainbow trout exposed to DEN and other carcinogens. In $\mathrm{H} \& \mathrm{E}$ stained sections, these foci in rainbow trout appear similar to this third type of focus in rivulus. However, results of procedures to demonstrate the perisinusoidal-stellate-cell characteristics of lipid-rich cells forming foci have not been reported for fish species other than rivulus.

Spongiosis hepatis in nvulus is histologicaliy similat to this lesion in nitrosomorpholine-treated rats (Bannasch et al. 1981). Bannasch et al. (1981) proposed that spongiosis hepatis is related to excessive production of glycosaminoglycans or protein by carcinogeninjured perisinusoidal cells. Extensive spongiosis hepatis invaded adjacent liver parenchyma in DENexposed sheepshead minnows Cyprinodon variegatus, suggesting that this type of lesion can progress to neoplasia in fish (Couch \& Courtney 1987).

Ectopic and enlarged thyroid masses in fish are diagnostic problems in fish because of difficulties in distinguishing between hyperplasia and neoplasia in this tissue. In fish, the thyroid is unencapsulated and normally located near the ventral aorta. Lesions that were probably thyroid hyperplasia occurred in rivulus in low temperature, Iow salinity environments (Harrington 1967). Ectopic follicles occur in liver, kidney, spleen, and several other organs of some fish species (Hoover 1984) but have not been observed in rivulus. Iodine deficiency and other nutritional or environmental conditions are causes of thyroid enlargement in fish (Hoover 1984). During our study, iodine concentrations in the water were not determined and no attempt was made to provide supplemental iodine to fish with thyroid enlargement. The lack of thyroid lesions in control rivulus during this study suggests that continuous DEN-exposure caused the thyroid lesions. The anaplastic thyroid tissue in livers of DEN-exposed rivulus suggests metastasis of a thyroid neoplasm; however, the question of whether the thyroid lesions in DENexposed rivulus are hyperplastic or neoplastic must await further study of fish thyroid tumors.

The carcinogenesis of some neoplasms in DENexposed rivulus is affected by the age of the fish at the beginning of exposure. In an earlier experiment, rivulus first exposed to DEN when they were less than 1 mo old had nearly twice the incidence of hepatocellular carcinoma as fish exposed when 6 mo old (Koenig \& Chasar 1984). Park \& Kim (1984) also reported a high 
incidence of liver tumors in rivulus exposed $3 \mathrm{~d}$ posthatching. Our study indicates that the incidences of cholangiocarcinomas and hemangiomas for rivulus first exposed when they were $1 \mathrm{~d}$ old was significantly higher than the incidence in rivulus first exposed when $30 \mathrm{~d}$ old. Also, a difference between age groups occurred in regard to pancreatic adenocarcinomas, which occurred only in rivulus first exposed when $1 \mathrm{~d}$ old (Thiyagarajah \& Grizzle 1986a).

A positive dose response for liver tumor formation occurred in 3-d-old rivulus exposed to DEN for $2 \mathrm{~h}$ (Park \& Kim 1984) and a threshold concentration for hepatic neoplasm development was found for adult rivulus (Koenig \& Chasar 1984). However, in our study no dose response or threshold was detected. Continuous exposure to the higher doses in our study could have caused impaired liver function and, therefore, reduced metabolism of DEN to its toxic and carcinogenic metabolites. Additional exposures with a wider range of DEN concentrations and with physiological measures of liver function are needed to verify this hypothesis

Hepatic neoplasms occur in rivulus exposed to DEN for only $2 h_{i}$ this is the shortest exposure time to DEN reported to cause neoplasms in any fish species (Park \& Kim 1984). Although single-exposure assays for carcinogenicity are easier to perform and reduce the safety hazard to laboratory personnel, continuous exposures of rivulus to DEN for several weeks or months result in a greater variety of neoplasms than exposures of $1 \mathrm{wk}$ or less (Koenig \& Chaser 1984, Park \& Kim 1984, Thiyagarajah \& Grizzle 1986a, present study). In the present study, hepatocellular and biliary neoplasms in continuously exposed fish were anaplastic and invasive more often than in fish exposed for only $1 \mathrm{wk}$.

In conclusion, rivulus are most susceptible to the oncogenic effects of DEN and they develop a wider variety of neoplasms if they are exposed when less than 1 mo old to a prolonged exposure ( $>1 \mathrm{wk}$ ). Because rivulus normally reproduce by self-fertilization, isogenic rivulus are available for tumor transplant studies, and variability within treatments may be less if isogenic fish are used. Another feature of this species is the presence of epidermal capillaries (Grizzle \& Thiyagarajah 1987), which probably increase cutaneous absorption of water-borne chemicals. Additional information is needed about this species' response to other carcinogens because of the unique biological features of this species which enhance its usefulness as a model animal for carcinogenesis testing.

Acknowledgements. This study was supported by the Southeastern Cooperative Fish Disease Project.

\section{LITERATURE CITED}

Argus, M. F., Hoch-Ligeti, C. (1961). Comparative study of the carcinogenic activity of nitrosamines. J. Natl Cancer Inst. 27: 695-709

Argus, M. F. Hoch-Ligeti، C. (1963). Induction of malignant tumors in the guinea pig by oral administration of diethylnitrosamine. J. Natl Cancer Inst. 30: 533-551

Ashley, L. M. Halver, J. E. (1963). Multiple metastasis of rainbow trout hepatoma. Trans. Am. Fish. Soc. 92: 365-371

Ashley, L. M., Halver, J. E. (1968). Dimethylnitrosamineinduced hepatic cell carcinoma in rainbow trout. J. Natl Cancer Inst. 41 531-552

Bannasch, P., Block, M., Zerban, H. (1981). Spongiosis hepatis. Specific changes of the perisinusoidal liver cells induced in rats by $N$-nitrosomorpholine. Lab. Invest. 44 : 252-264

Bannasch, P., Mayer, D., Hacker, H. J. (1980). Hepatocellular glycogenosis and hepatocarcinogenesis. Biochim. Biophys. Acta $605: 217-245$

Couch, J. A., Courtney, L. A. (1987). N-Nitrosodiethylamineinduced hepatocarcinogenesis in estuarine sheepshead minnow (Cyprinodon variegatus): neoplasms and related lesions compared with mammalian lesions. J. Natl Cancer Inst. 79: $297-321$

Egami, N., Kyono-Hamaguchi., Y., Mitani, H., Shima, A. (1981). Characteristics of hepatoma produced by treatment with diethylnitrosamine in the fish, Oryzias latipes. In: Dawe, C. J. et al. (eds.) Phylogenetic approaches to cancer Japan Sci. Soc. Press, Tokyo, p. 217-226

Grizzle, J. M., Thiyagarajah, A. (1987). Skin histology of Rivulus ocellatus marmoratus: apparent adaption for aerial respiration. Copeia 1987 $237-240$

Harrington, R. W., Jr (1967). Environmentally controlled induction of primary male gonochorists from eggs of the self-fertilizing hermaphroditic fish, Rivulus marmoratus Poey. Biol. Bull. mar. biol. Lab., Woods Hole 131: 174-199

Hendricks, J. D., Meyers, T R., Shelton, D. W (1984). Histological progression of hepatic neoplasia in rainbow trout (Salmo gairdneri). Natl Cancer Inst. Monogr. 65: 321-336

Hoover, K. L. (1984). Hyperplastic thyroid lesions in fish. Natl Cancer Inst. Monogr. 65: 275-289

Humason, G. L. (1979). Animal tissue techniques, 4th edn. W. H. Freeman and Co., San Francisco

Ishikawa, T., Shimanura, T., Takayama, S. (1975). Histologic and electron microscopic observation on diethylnitrosamine-induced hepatomas in small aquarium fish (Oryzias latipes). J. Natl Cancer Inst. 55: 909-916

Kelly, M. G., O'Gara, R. W., Adamson, R. H., Gadekar, K. Botkin, C. C., Reese, W. H., Jr, Kerber, W. T. (1966). Induction of hepatic cell carcinoma in monkeys with $\mathrm{N}$ nitrosodiethylamine. J. Natl Cancer Inst. 36: 323-351

Khudoley, V V. (1984). Use of aquarium fish, Danio rerio and Poecilia reticulata, as test species for evaluation of nitrosamine carcinogenicity. Nath Cancer Inst. Monogr 65: $65-70$

Koenig, C. C., Chasar, M. P. (1984). Usefulness of the hermaphroditic marine fish, Rivulus marmoratus, in carcinogenicity testing. Natl Cancer Inst. Monogr. 65: 15-33

Lunn, G., Sansone, E. B., Keefer, L. K. (1983). Safe disposal of carcinogenic nitrosamines. Carcinogenesis 4: 315-319

Park, E. H., Kim, D. S. (1984). Hepatocarcinogenicity of diethylnitrosamine to the self-fertilizing hermaphroditic fish Rivulus marmoratus (Teleostomi: Cyprinodontidae). J. Natl Cancer Inst. 73: 871-876 
Pariand, W. K., Baumann. P. C. (1985). Pathology and tumor development through time in guppies dosed with diethylnitrosamine (DEN). J. appl. Toxicol. 5: 265-272

Rapp, H. J., Carleton, J. H., Crisler, C., Nadel, E. M. (1965). Induction of malignant tumors in the rabbit by oral administration of diethylnitrosamine. J. Nat] Cancer Inst. 34: $453-458$

Schultz, M. E. Schultz, R. J. (1985). Transplantable chemically-induced liver tumors in the viviparous fish Poecillopsis. Exp. mol. Pathol. 42: 320-330

Seegers, L. (1.984). Zur Revision der Rivulus-Arten SüdostBrasiliens, mit einer Neubeschreibung von Rivulus luelingi $\mathrm{n}$. sp. und Rivulus caudomarginatus n. sp. (Pisces: Cyprinodontidae: Rivulinae). Zool. Beitr. 28: 271-320

Sinnhuber, R. O., Hendricks, J. D., Wales, J. H., Putman, J. B. (1977). Neoplasms in rainbow trout, a sensitive animal model for environmental carcinogenesis. Ann. N.Y Acad. Sci. 298: 389-408
Stanton, M. F. (1965). Diethylnitrosamine-induced hepatic degeneration and neoplasia in the aquarium fish, Brachydanio rerio. J. Natl Cancer Inst. 34: 117-130

Stewart, H. L., William, G., Keysser, C. H. et al. (1980). Histologic typing of liver tumors in the rat. J. Natl Cancer Inst. 64: 179-206

Thiyagarajah, A., Grizzle, J. M. (1985). Pathology of diethylnitrosamine toxicity in the fish Rivulus marmoratus. J. environ. Pathol. Toxicol. Oncol. 6: 219-232

Thiyagarajah, A., Grizzle, J. M. (1986a). Diethylnitrosamineinduced pancreatic neoplasms in the fish. Rivulus ocellatus marmoratus. J. Natl Cancer Inst. 77: 141-147

Thiyagarajah, A., Grizzle, J. M. (1986b). Nuclear glycogen and lipid in hepatocytes of a fish, Rivulus ocellatus marmoratus. Can. J. Zool. 64: 2868-2870

Wake, K. (1971). 'Sternzellen' in the liver: perisinusoidal cells with special reference to storage of vitamin A. Am. J. Anat. 132: $429-462$

Responsible Subject Editor: Professor N. Peters; accepted for printing on June 17, 1988 